\title{
Elevated Bloom's Taxonomy; Complete Learning through Sensors
}

\author{
*Dr. S. Altaf Hussain \\ Director, Lords Institute of Engineering \& Technology, Hyderabad- 500091. \\ Email: altaf.che@gmail.com, Mobile: 9440425786

\section{Dr. Ghousia Begum}

Sr. Principal Scientist, CSIR-Indian Institute of Chemical Technology, Hyderabad- 500 007, Email: ghousia101@gmail.com, Mobile:9177775686

\author{
Dr. S. V. Satyanarayana \\ Professor of Chemical Engineering, JNTUA, Anantapur, 515002, \\ Email:svsatya7@gmail.com, Mobile:9849509167
}

\begin{abstract}
:
India is known for Learning with appropriate methodologies. Vedas, Upanishads are the world treasure of knowledge. Ancient Guru's used to teach students, with applicative skills, where at the end of the course students are fully equipped with knowledge and wisdom towards execution. Though lot of universities has been designing curriculum, with an objective to meet the real life applications, yet the efficiency of most of the graduates are not meeting, barring graduates of few institutes. Bloom's Taxonomy describes about Learning concepts like Remembering, Understanding, Applying, Analyzing, Evaluating, Creating in 'Cognitive' domain., Physical movements, coordination of human body with muscle movement in 'Psycho motor' domain., as well as feel the pain or joy in 'Affective' domain. Blooms Taxonomy is widely accepted by most of the Universities across the globe, and is successful upto some extent only, as lot more is required in learning process.
\end{abstract}

In current era, the overall efficiency of most of the graduates is not meeting employer expectations / real life applications, as $20 \%$ of overall learning is only taking place with the sensorization of approximately two of the human body sensors only out of five sensors governed by master sensor the mind. Blooms Taxonomy couldn't stress on essential learning through sensors and there is not much emphasis given about learning in physiological point of view through human body sensors, therefore the current methodology of learning enunciates about Elevated Bloom's Taxonomy, where complete learning takes place through sensorization of Human Body Sensors including ear, nose, eye, mouth, skin and mind through seven stages of learning. The results of sensorized learning of 7 different batches of students proved to be phenomenal. It is also hoped that, sensorized learning will give confidence to students / learners to earn while learning.

Key Words: Learning, Bloom's Taxonomy, Knowledge, Training 


\section{Introduction:}

Learning is a perpetual activity of every human being. Lot of research has been done towards establishing best method of learning and out of so many research outcomes Bloom's Taxonomy is considered to be highly popular even current times in learning domain. Benjamin Bloom a philosopher and an academician has proposed a theory in the year 1956 along with Max Englehart, Edward, Walter Hill and David Krathwohlput. Blooms Taxonomy consists of three areas of learning viz. Cognitive, Affective and Psychomotor (Bloom 1956). Later in the year 2001, revised Bloom's Taxonomy was published by Bloom's student Lorin Anderson along with Krathwohl (Anderson, Krathwohl \& Blooms, 2001). Effectiveness of Learning depends on complete personality development of an individual, which is proposed in Vedic Sciences as Achara Rasayana, which describes about physical fitness, mental soundness, emotional balance, social wellbeing and spiritual enrichment (Achara Rasayana, Shreeram Kumavat, Archana Verma, Sunil Yadav, KL Meena). Overall personality development and effectiveness of an individual is proposed by Human Excellence Index, where individual efficiency is evaluated through a scale of 1000 points in Courage / Defense Scale, Etiquette Scale, Patience Scale, Service/Technology/Innovation Scale, Loyalty Scale, as well as a negative scale (Altaf Hussain, Ghousia Begum, SV Satyanarayana 2020). As per aspiring minds report in 2019, which is now called as SHL, India has 6214 engineering and technology institutions, producing 1.5 million engineers, out of which $7 \%$ are only employable(www.shl.com). BW Education claims less than $20 \%$ engineering graduates are capable of employment(www.bweducation.businessworld.in)

Current article proposes elevated Bloom's Taxonomy, as detailed connection to different human body sensors is missing, which is currently bridged by way of carrying experimental study of performance of different student groups, through implementation of sensorized learning. Human body has five sensors, and as per the established literature, learning takes place through senserization. Top Universities / Institutes like MIT / Harvard / Stanford / Oxford / Cambridge / IIT's / NIT's / IIM's / ISB / AIMS, effective measures are being taken towards enriching the students through senserization of all human body sensors, but such sensorized learning is missing in most of the institutes, Hence proposal of this article for better learning of all students in all institutes / universities / Learning platforms.

\section{Methodology :}

Selection of Student Group: Over fifteen years, students of different groups were chosen and taught technical concepts till the level of producing final compound / object, by way of sensitizing through five human body sensors viz, ear, eyes, nose, mouth, skin, and the efficiency at different levels has been evaluated.

\section{Preliminary Analysis on Why A Student Fails:}

Students who are considered to be irregular and mischievous in nature are chosen, and analyzed, why they are being failed. Analysis techniques include getting inputs from peer group / relatives / friends /environment, as well as from Parents and Teachers. It is the proven 
statistical fact that $80 \%$ of the students concentrate only 'one' stage of learning out of seven stages. Following methodology was also used in assessing student's credentials:

\section{Assessment Tools:}
1. Predictive Analysis of Student
2. Preventive Analysis of Students
3. Corrective Analysis of Student
4. Bottle necks \& De-Bottle necks
5. Gentle Communication Skills
6. Techno Analytical Reading skills
7. Technical Writing skills
8. Listening skills
9. Technical Speaking skills
10. Body language
11. Gestures
12. Overcoming evil qualities
13. Social arts
14. Negotiation skills
15. Problem solving skills
16. Positive thinking
17. Thematic appreciation tests
18. Press meet skills
19. Professional Ethics
20. Goal Setting skills
21. Health Management
22. Human Relations
23. Memory skills
24. Meditation skills

25. Stress Management skills

26. Failure Management skills

27. Aculturaistion

28. Thinking abilities

29. Talent Exploration \& Career Guidance

30. Bad Habits

31. Peer Pressure Management skills

33. Anger Management skills

34. Sensible Sex Education with Threshold Limits

35. Validation of Professionalism

36. Psychological Tests / IQ Test

37. Physical Fitness skills

38. Deficiency - Introspection

39. Social Project / Applicative skills

40. Publication skills

Table 1: Assessment tools to evaluate student / learners state of position

All the above mentioned 40 areas are assessed in four grading's. (1). Less than $25 \%$ performance (2). More than $25 \%$ but less than $50 \%$ (3). More than $50 \%$ but less than $75 \%$ (4). More than $75 \%$ but less than $100 \%$.

\section{Sensorized Learning:}

Students were taught the technical concepts through different techniques, by way of activating / feeding through sensors viz . reading / listening, Writing, seeing images/ objects/things, speaking / discussing, doing things practically, Observing, and Validating by self as well as others / experts . A selected seven group of students performance is studied for the research. For all the groups different task of learning and producing was given, and assessment has been done seven times for 100 marks each, and the efficiencies were analyzed during above mentioned seven stages, and the efficiencies were improving, as they were exposed to sensorized learning. The task given to group ' $A$ ' is "Effective Utilization of Compressor", the task given to group ' $\mathrm{B}$ ' is "Natural Air Conditioner", the task given to group ' $\mathrm{C}$ ' is 'Instant Heat Transfer", the task given to group ' $\mathrm{D}$ ' is "production of natural pranayamizer", the task given to group ' $\mathrm{E}$ ' is "comparison of plastic / paper bags", the task 
given to group ' $F$ ' is "dis-infection of municipal water", the task given to group ' $G$ ' is "sterilization of indoor air through Homam". Initially all the students were asked to read the concept/task and write their level of understanding on paper, and was evaluated. Secondly students were asked to re-write what has been understood, and was evaluated. Thirdly students were asked to see / watch Video Demonstrations as well as laboratory experiment functioning and was asked to write on the concept learnt, and was evaluated. Fourthly, students were made to discuss each other / explain / demo, and was evaluated. Fifthly, students were made to prepare the model / prototype and explain, while doing so students were asked to note down the sensory observations including sound intensity, sound rhythm, smell, colour / image, temperature and was evaluated. Sixthly, students were made to Observe the functioning of the model/prototype and fine tune, which was then evaluated. Seventhly the students were exposed to National Competitions, and could explain comfortably.

\section{Results \& Discussions:}

The seven groups of students were preliminarily with their general performance in 40 assessment tools, as mentioned in Table 1. The average performance of students of all seven groups is found to be less than $25 \%$, and training on several concepts connecting all sensors till production of product and analysis is given.

Following is the results of performance / learning efficiency of different group of students, in their learning process:

\begin{tabular}{|l|ll|l|l|l|l|l|l|l|}
\hline S.No & $\begin{array}{l}\text { Activity } \\
\text { Sensorization }\end{array}$ & $\begin{array}{l}\text { Group } \\
\text { A } \\
\text { student } \\
\text { s } \\
\text { efficien } \\
\text { cy } \\
\%\end{array}$ & $\begin{array}{l}\text { Group } \\
\text { B } \\
\text { student } \\
\text { s } \\
\text { efficien } \\
\text { cy\% }\end{array}$ & $\begin{array}{l}\text { Group } \\
\text { C } \\
\text { student } \\
\text { s } \\
\text { efficien } \\
\text { cy\% }\end{array}$ & $\begin{array}{l}\text { Group } \\
\text { D } \\
\text { student } \\
\text { s } \\
\text { efficien } \\
\text { cy\% }\end{array}$ & $\begin{array}{l}\text { Group } \\
\text { E } \\
\text { student } \\
\text { s } \\
\text { efficien } \\
\text { cy\% }\end{array}$ & $\begin{array}{l}\text { Group } \\
\text { F } \\
\text { student } \\
\text { s } \\
\text { efficien } \\
\text { cy\% }\end{array}$ & $\begin{array}{l}\text { Group } \\
\text { student } \\
\text { s } \\
\text { efficie } \\
\text { ncy\% }\end{array}$ \\
\hline 1 & $\begin{array}{l}\text { Reading } \\
\text { Listening }\end{array}$ & 13 & 16 & 15 & 18 & 12 & 18 & 16 \\
\hline 2 & Writing & 32 & 29 & 31 & 30 & 33 & 31 & 29 \\
\hline 3 & Seeing & 46 & 45 & 44 & 46 & 48 & 50 & 44 \\
\hline 4 & Speaking & 59 & 60 & 62 & 62 & 64 & 61 & 60 \\
\hline 5 & $\begin{array}{l}\text { Doing } \\
\text { Producing }\end{array}$ & 76 & 75 & 72 & 78 & 72 & 76 & 74 \\
\hline 6 & Observing & 89 & 91 & 90 & 93 & 94 & 84 & 92 \\
\hline 7 & Validating & 95 & 96 & 99 & 97 & 98 & 93 & 99 \\
\hline
\end{tabular}

Table 2: Learning Efficiencies of 7 batches of students

The learning efficiencies of 7 batch students were estimated, during all times of learning for 100 marks each and were tabulated. All the students proved them self with progressive learning as they exposed to different sensors. 


\section{The Sensorized Learning Sphere:}

The Authors have referred famous Bloom's Taxonomy, and proposing the current "Sensorized Learning Sphere" towards better learning of Individuals / students. An individual can learn upto $15 \%$ by reading / listening as a first spell of sensorization, and develops concept by way of writing upto $30 \%$, furthermore develops by way of seeing images, objects, things upto $45 \%$, and further develops upto $60 \%$ by way of speaking and discussing, and further develops upto $75 \%$ by way of doing things practically and further develops upto $90 \%$ by way of Observing and finally develops $100 \%$ Learning by way of Validating by self as well as others / experts.

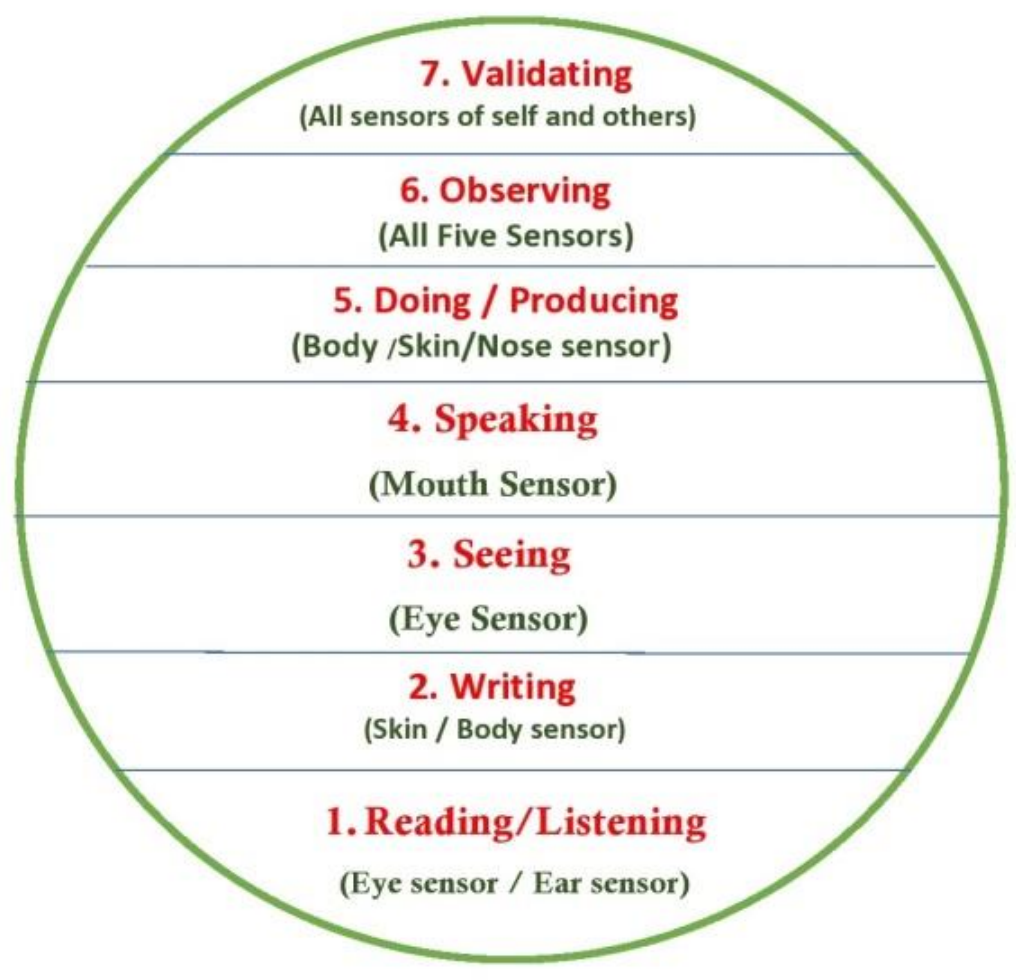

Figure 1: Proposed Sensorized Learning Sphere

In current academic practices, learning taking place through limited Reading, limited Listening, limited Writing and Doing limited practical's only, and lots of real learning through sensorization is not taking place, in-turn sluggishing the overall efficiency of learner. Therefore The Authors propose the Sensorized Learning Sphere to be implemented at all institutions.

The teachers should teach creatively meeting all the above mentioned seven areas, where complete learning and development takes place.

The success of a student depends on i. Peer Group / Relatives / Friends, ii. Parents and iii.Teachers, which is called success Triangle. Infact student is a mere follower only, who receive inputs from the above three and act accordingly. If the student is successful, the first credit goes to Peer Group / Relatives / Friends / Environment, secondly Parents and thirdly Teachers. Similar is the case with student's failure. 


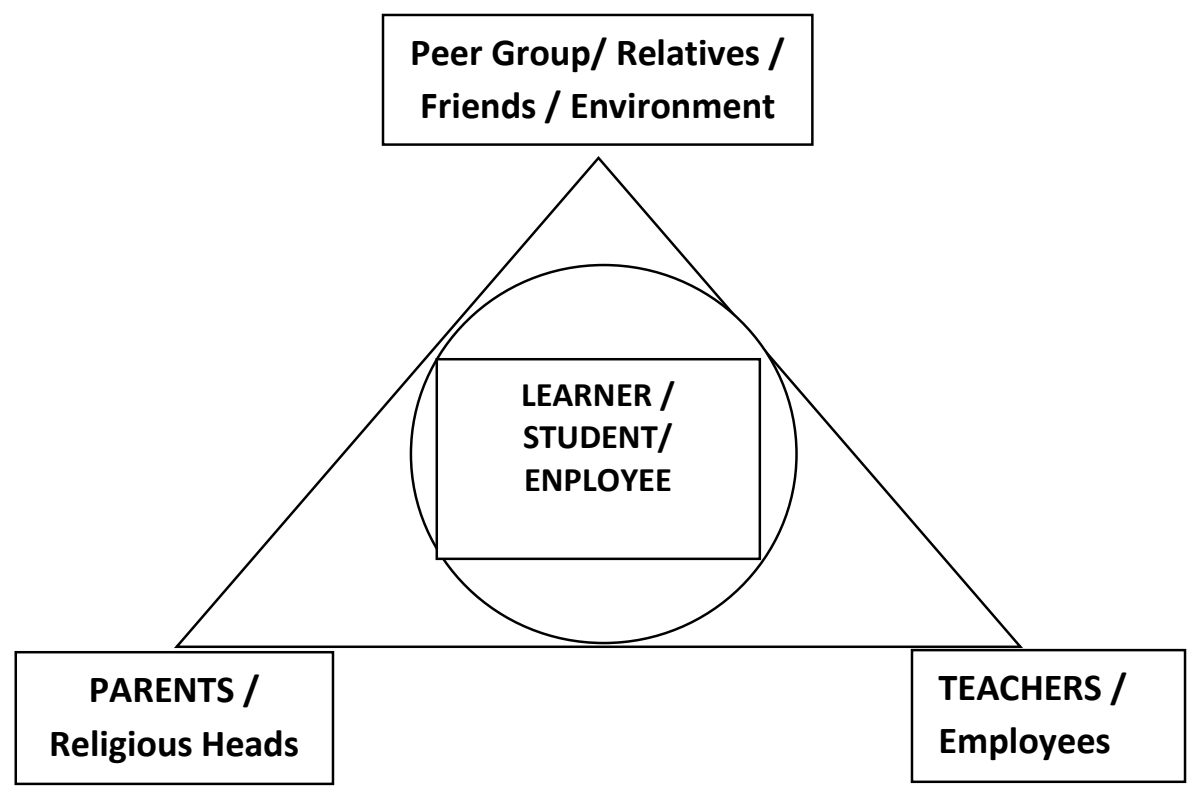

Figure 2 : Proposed Success Triangle

It is the cold fact that almost all the students bluff their parents by one way or other. If the student is cognizant enough, he/she would correct him/herself and proceed in right path, whereas students who don't think will miserably fail. Student(s) fail due to instigations / influences by peer group as well as relatives for their selfish sake.

\section{Responsibility of Parents / Teachers / Employers:}

Parents and Teachers are not taking complete responsibility to nurture their ward(s) / student(s). Similarly very less care is being taken in nurturing the employees. In current era of hectic life style, almost all the parents and teachers are fully occupied with their occupational stresses, and are not finding adequate time for nurturing the students in a systematized way. Each teacher should be entrusted with 20 students to mentor. It is the responsibility of Teacher to shoulder the responsibility as the Professional Guardian. It is the responsibility of both Parents and Students to assess the performance of ward(s) / student(s) on a continuous basis at-least every fortnightly and ensure success in all endeavors (Achara Rasayana)

\section{Recognition to Parents / Teachers:}

Each teacher / mentor must be allotted with 20 students. The mentor teacher will serve as the professional Guardian. At the end of the semester, the teachers efforts will yield with good results of all his/her 20 students. The efforts of teacher / mentor should be recognized by the institute. Similarly the efforts of parents must be recognized by the institute. The recognition can be in the form of Single Star, Doubble Star, Tripple Star, Quartarble Star, Quintible Star / Five Star. The single star will be given to teacher / mentor as well as both parents upon successful completion of the semester with 70+ percentage of marks of their ward / 70+ percentage of marks by all 20 students of Teacher / Mentor, Two star can be encouraged for co-curricular accomplishments in local level. Three star can be encouraged for co-curricular 
accomplishments in state level. Four star can be encouraged for co-curricular accomplishments in National Level. Similarly five star to be given to teacher / mentor as well as both parents upon successful completion of any project / task at international level, which will be regarded high.

\section{Optimal Diet and Behavioural Monitoring:}

Diet is an essential component which governs physical and mental performance of an individual. Consumption of Non Vegetarian on a regular basis is strictly prohibited, nevertheless one can consume 100 gram per week. Excess consumption of Non Vegetarian leads to evil qualities like Kama, Krodha, Lobha, Mada, Mohana and Matsa. Optimal diet will optimize functioning of Sympathetic nerves as well as Para Sympathetic nerves(Achara Rasayana).

\section{How to overcome Negative Qualities:}

If the student is counseled in above mentioned 40 Assessment Areas, he / she will overcome negative qualities (Achara Rasayana, Human Excellence Index).

Nurturing Good Habits: It is the responsibility of Parents / Teachers / Employers to teach / counsel what is good and what is bad. They should also teach threshold limit values in personal life as well as professional life. Most of the students commit mistakes as they are ignorant, therefore parents and teachers must sensitize in all aspects of learning(Achara Rasayana).

\section{Memory / Concentration Boosters:}

Brahmi / Saraswati leaves as well as Almonds and Walnut were found to be memory boosters. Meditation and Pranayamam were also found to be memory boosters. Therefore parents and teachers are advised to administer.

Example of Sensorized Learning for the benefit of Parents / Teachers / Employers:

Topic of Learning: Classification of Pumps

Stage 1: The Teacher will explain to the students/learners or The students / learners will read, where eye and ear sensorization takes place.

Stage 2: The students /learners will note down salient points about what has been understood in Stage 1 while listening / reading about Classification of Pumps, where skin / mind sensorization takes place.

Stage 3: The students / learners will see the objects / pictures / videos pertaining to classification of pumps in laboratory, text books, videos, industry etc., The salient points of the same will be noted down, where eye sensorization with impact takes place.

Stage 4: The group of students will discuss and explain to each other what they have observed. The salient points will be noted down, where mouth / mind sensorization takes place.

Stage 5: The group of students / learners will draw the pictures, on note book or in 3D digital drawing with some innovation / modification or observe the performance in laboratory by varying parameters and salient points including vibration / movement, sound, smell, taste observed are noted down, where eye/mouth/mind/nose/skin sensorization takes place. The 
students will also be producing products, which will also bring probable revenue while learning.

Stage 6: The group of students / learners will re do the things of stage 5, and produce things., while doing so, observe practically about the innovations done, and the salient points will be discussed, and salient points including vibration / movement, sound, smell, taste observed are noted down, where eye/mouth/mind/nose/skin sensorization takes place.

Stage 7: The overall observations and developments will be validated by the Teacher / Mentor and further validated by the Head / Chief Mentor and should awards marks accordingly.

\section{Constant Learning by Student / Learner:}

The student / learner should keep one exclusive note book for each course. On an average each semester will have five theory courses and two laboratory courses, therefore the student/learner should keep total seven note books, and each book should be divided into $1 / 3$ and $2 / 3$. First portion of $1 / 3$ note book is meant for noting down class room content i.e stage 1 learning., and second portion of $2 / 3$ note book is meant for self-notes preparation, which includes stage 2, stage 3, stage 4, stage5, stage6 and stage 7 learning. Eg, if the note book has 200 pages, first 70 pages are to be spared for noting salient points discussed in class room, and next 130 pages are to be spared for writing self-notes. Model note book is shown as example in Table 3.

A note book of 200 pages is to be divided into two portions ie page 1-70 class notes to be written. Page 71-200 self- notes to be written as shown in Table 3.

\begin{tabular}{|c|c|}
\hline $\begin{array}{c}\text { Class Notes as understood in class to be } \\
\text { written } \\
\text { Page } 1 \text { to Page } 70 \text { of } 200 \text { page note book } \\
\text { (Stage } 1 \text { and partly few other stages of } \\
\text { learning) }\end{array}$ & $\begin{array}{l}\text { Self-notes as understood to be written } \\
\text { Page } 71 \text { to } 200 \text { of } 200 \text { pages } \\
\text { (Stage } 2 \text { to stage } 7 \text { of learning) }\end{array}$ \\
\hline \multirow{2}{*}{$\begin{array}{l}\text { Eg. } \\
\text { Page } 1 \\
\text { Syllabus needs to be written preferably / } \\
\text { print copy to be pasted. }\end{array}$} & $\begin{array}{l}\text { Page } 71 \text { (first half page) } \\
\text { Documenting stage ' } 2 \text { ' learning on pumps }\end{array}$ \\
\hline & $\begin{array}{l}\text { Page } 71 \text { (second half page) } \\
\text { Documenting stage ' } 3 \text { ' learning on pumps }\end{array}$ \\
\hline \multirow[t]{2}{*}{$\begin{array}{l}\text { Page } 2 \\
\text { Class Time Table to be pasted }\end{array}$} & $\begin{array}{l}\text { Page } 72 \text { (first half page) } \\
\text { Documenting Stage ' } 4 \text { ' learning on pumps }\end{array}$ \\
\hline & $\begin{array}{l}\text { Page } 72 \text { (second half page) } \\
\text { Documenting Stage ' } 5 \text { ' learning on pumps }\end{array}$ \\
\hline $\begin{array}{l}\text { Page } 3 \\
\text { Semester Plan including examination }\end{array}$ & $\begin{array}{l}\text { Page } 73 \text { (first half page) } \\
\text { Documenting stage ' } 6 \text { ' learning on pumps }\end{array}$ \\
\hline
\end{tabular}




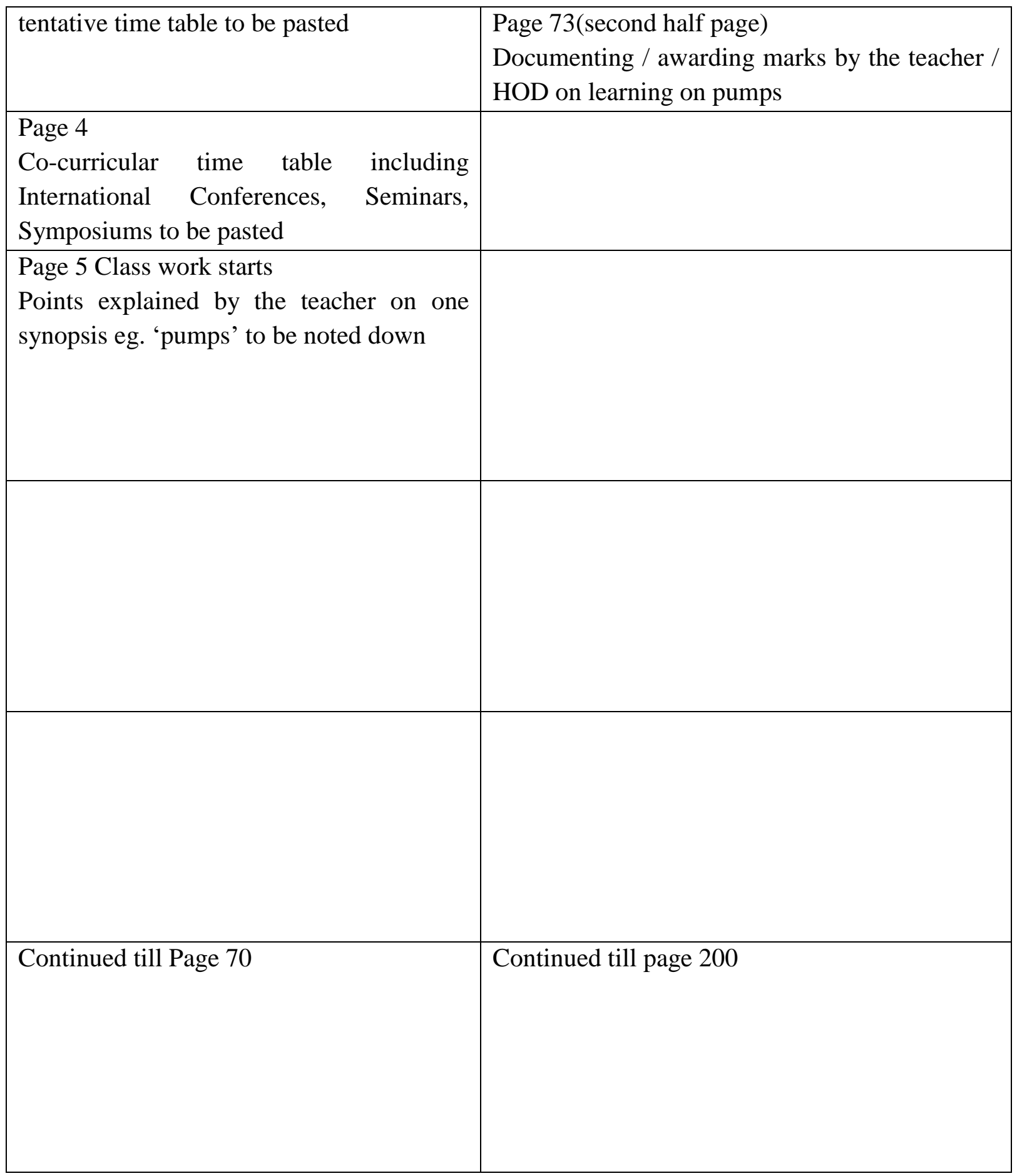

Table 3: Model Note book at a glance to be maintained by the student / learner

Procedure to maintain self- notes by learner / student, explanation of Table 3:

Stage 1: Student should write the concepts understood in class room

Stage 2: Student should write the concepts by applying his/her interpretations in second portion of note book, in a separate page / column mentioning stage 2 learning.

Stage 3: Student should write the concepts by applying his/her interpretations in second portion of note book, in a separate page / column mentioning stage 3 learning.

Stage 4: Student should write the concepts by applying his/her interpretations in second portion of note book, in a separate page / column mentioning stage 4 learning. 
Stage 5: Student should write the concepts by applying his/her interpretations in second portion of note book, in a separate page / column mentioning stage 5 learning.

Stage 6: Student should write the concepts by applying his/her interpretations in second portion of note book, in a separate page / column mentioning stage 6 learning.

Stage 7: Student should get it corrected by the teacher. It is the responsibility of the teacher / HoD to correct and sign in the note book.

\section{Constant Monitoring by Parents \& Teachers:}

In current era of hectic schedule, neither parents nor teachers are finding time to administer all seven areas of learning. The parents and teachers should prepare a semester calendar of their ward / student, and monitor the performance in 40 assessment areas once in a year as well as the following seven areas once in a month viz.

1. Reading / Listening

2. Writing

3. Seeing

4. Speaking

5. Doing / Producing

6. Observing

7. Evaluating

With the influence of peer group as well as family / relatives, the student / learner may not respond some times, therefore such instances as per Vedic Sciences, the student requires Sam, Dam, Dand and Bhed technique to be adopted, and the same technique is to be adopted to all the peer group as well as family / relatives who are responsible in negatively influencing.

\section{Overall Personality Development of Student:}

The Teachers and Parents should take the responsibility of nurturing the overall personality of student as per 40 assessment tools.

\section{Conclusions:}

Complete learning of student / learners takes place through proper inputs into brain / mind through all five sensors. Bloom's Taxonomy explained through three domains viz. Cognitive, Affective and Psychomotor, but couldn't explained sensibly about the essential need of learning through sensors viz., Ear, Mouth, Eyes, Nose and Skin, governed by mind, while documenting in each stage. The authors recommend Institutions and Universities to design the syllabus meeting all seven areas of learning viz. Reading / Listening, Writing, Seeing, Speaking, Doing/Producing, Observing and Evaluating. It is also recommended to all the teachers / parents / employers to evaluate the state of position of student / learner once in a year. There is a hope and scope that, the student / learner will be able to earn revenue while learning. 


\section{Acknowledgements:}

The authors deeply express their Gratitude's to the management of BVRIT Narsapur, JNTU Anantapuram, and Lords Institute of Engineering \& Technology, Hyderabad.

The Authors recommend all the readers to refer the pertinent publications in nurturing the wards / students / Learners in building overall personality in turn building the organization / Nation.

\section{References:}

1. Anderson, L.W., \& Krathwohl, D.R. (Eds.), 2001, A taxonomy for learning, teaching and assessing; A revision of Bloom's Taxonomy of educational objectives; Complete edition, New York; Longman.

2. Bloom, Benjamin S. \& David R. Krathwohl, 1956. Taxonomy of educational objectives; The classification of educational goals, by a committee of college and university examiners. Handbook 1, Cognitive domain, New York, Longmans.

3. Shreeram Kumawat, Archana Verma, Sunil Yadav, K.L. Meena, Achara Rasayana- A behavioral Therapy in Ayurveda to Promote Health and Happiness, Jan 2018, International Journal of Ayurveda and Pharma Research

4. S. Altaf Hussain, Ghousia Begum, SV Satyanarayana, 2020 Human Excellence Index, AIJRRSLSSJMP.

5. $7 \%$ of engineering graduates only possess employable skills. $\underline{w w w . s h l . c o m}$

6. Less than $20 \%$ engineering graduates are only capable of employment www.bweducation.businessworld.in

7. BS Throat, TA Bagkar and RR Patil, Brahmi, The memory booster medicinal herb, Journal of Medicinal Plant studies 185-187.

8. Sakshi Singh, Asmita Gautam, Abhimanyu Sharma and Amla Batra, Centella Asiatica(L), A Plant with immense medicinal potential but threatened, International Journal of Pharmaceutical Sciences Review and Research, Page 9-17, 2010

9. Mission 10 X learning material by Wipro, 2010. 